\title{
CpG island methylation profile of pancreatic intraepithelial neoplasia
}

\author{
Norihiro Sato, Noriyoshi Fukushima, Ralph H Hruban and Michael Goggins \\ Departments of Pathology, Oncology and Medicine, The Sol Goldman Pancreatic Cancer Research Center, \\ The Johns Hopkins Medical Institutions, Baltimore, MD, USA
}

\begin{abstract}
Infiltrating adenocarcinoma of the pancreas is thought to develop through well-defined precursor lesions called pancreatic intraductal neoplasia (PanIN). Despite the exponential growth in our understanding of genetic events that characterize the progression of PanINs to invasive carcinoma, little is known about the role of epigenetic alterations in these precursor lesions. To define the timing and prevalence of methylation abnormalities during early pancreatic carcinogenesis, we investigated the CpG island methylation profile in the various grades of PanINs. Using methylation-specific PCR, we analyzed DNA samples from 65 PanIN lesions for methylation status of eight genes recently identified by microarray approach as aberrantly hypermethylated in invasive pancreatic cancer. Aberrant methylation at any of the eight genes was identified in $68 \%$ of all the PanIN lesions examined, and, notably, aberrant methylation was identified in more than $70 \%$ of the earliest lesions (PanIN-1A). The average number of methylated loci was 1.1 in PanIN-1A, 0.8 in PanIN-1B, 1.1 in PanIN-2, and 2.9 in PanIN-3 lesions ( $P=0.01$ for PanIN -3 vs earlier PanINs). Among the genes analyzed, NPTX2 demonstrated an increase in methylation prevalence from PanIN-1 to PanIN-2 $(P=0.0008)$, and from PanIN-2 to PanIN-3 for SARP2 $(P=0.001)$, Reprimo $(P=0.01)$, and $L H X 1(P=0.03)$. These results suggest that aberrant CpG island hypermethylation begins in early stages of PanINs, and its prevalence progressively increases during neoplastic progression.
\end{abstract}

Modern Pathology (2008) 21, 238-244; doi:10.1038/modpathol.3800991; published online 21 December 2007

Keywords: PanIN; pancreatic cancer; methylation specific PCR; DNA methylation

Accumulating evidence supports the hypothesis that infiltrating adenocarcinoma of the pancreas develops from noninvasive precursor lesions in the small ducts and ductules, called pancreatic intraductal neoplasia (PanIN). ${ }^{1,2}$ Characterization of molecular basis for these precursor lesions may refine our understanding of pancreatic ductal carcinogenesis and also provide important insight into early pancreatic cancer detection strategies and novel targets for chemoprevention. ${ }^{3}$ Many of the genetic abnormalities observed in invasive pancreatic cancer have also been observed in PanIN lesions. The reported genetic alterations in PanINs include activating point mutations in the KRAS2 oncogene $^{4}$ and inactivation of p16/CDKN2A, ${ }^{5}$ TP53, ${ }^{6}$ SMAD4/DPC4, ${ }^{6,7}$ and BRCA2., ${ }^{2,8,9}$ Most of these genetic alterations have been detected in the histologically more advanced PanIN lesions

Correspondence: Dr M Goggins, MD, Departments of Pathology, Medicine, and Oncology, The Johns Hopkins Medical Institutions, Cancer Research II Building, 1550 Orleans Street, Baltimore, MD 21231, USA.

E-mail: mgoggins@jhmi.edu

Received 4 September 2007; accepted 1 October 2007; published online 21 December 2007
(PanIN-2 and PanIN-3), and the initiating events in neoplastic progression within the pancreatic ducts remains unknown. In addition, telomere shortening is a common genetic abnormality observed in all stages of PanINs including the vast majority of earliest lesions (PanIN-1A). ${ }^{10}$

PanIN lesions may be particularly important in patients with a strong family history of pancreatic cancer. ${ }^{11-13}$ Pancreata in patients with a strong family history of pancreatic cancer are remarkable for the presence of multifocal PanIN lesions, and these PanIN lesions are characteristically associated with a distinctive form of lobular parenchymal atrophy and are closely associated with the subtle EUS abnormalities seen in this group. ${ }^{11}$ Identifying molecular markers of PanIN could be particularly valuable for these individuals. ${ }^{12,13}$

Aberrantly methylated genes is a particularly promising category of molecular markers of neoplasia. Aberrant CpG island hypermethylation is associated with the inactivation of critical tumorsuppressor genes in human cancers. ${ }^{14}$ We have reported previously that many invasive pancreatic cancers harbor aberrant methylation of multiple genes. ${ }^{15-42}$ Aberrant methylation of several genes has also been observed in intraductal papillary 
mucinous neoplasms of the pancreas, ${ }^{43}$ and in a subset of PanIN lesions. ${ }^{44-46}$ For example, we previously reported that $p p E N K$ is aberrantly methylated in $16 \%$ of 102 PanINs and that the prevalence of methylation increases with PanIN grade. ${ }^{44}$ These findings suggest an important role of $\mathrm{CpG}$ island hypermethylation in early pancreatic carcinogenesis. We have also found that methylation of genes commonly methylated in pancreatic ductal adenocarcinomas is readily detectable in pancreatic juice samples of patients with invasive pancreatic cancer and can help distinguish patients with benign vs malignant pancreatic disease. ${ }^{26,28,32}$ Sensitive and specific markers of PanIN would be a further advance as they could help identify curable preinvasive neoplasia among individuals at increased risk of developing pancreatic cancer who are undergoing screening. However, the prevalence of aberrant methylation of many genes in PanINs is not known.

To further characterize the timing and prevalence of aberrant DNA methylation during pancreatic ductal carcinogenesis, we investigated the CpG island methylation profile in various grades of PanINs. Using methylation-specific PCR, we analyzed DNA samples from a total of 65 PanIN lesions for methylation status of 8 genes that we identified and characterized as aberrantly hypermethylated in invasive pancreatic cancer.

\section{Materials and methods}

\section{Tissues samples}

Formalin-fixed paraffin-embedded blocks of resected pancreata from patients with various pancreatic disorders were collected from the archives of the Johns Hopkins Hospital and selected for microdissection of PanIN lesions. This study was approved by the Johns Hopkins Institutional Review Board. PanIN lesions were classified into PanIN-1A, PanIN-1B, PanIN-2, and PanIN-3 by two authors (NF and $\mathrm{RHH}$ ), according to the previously described criteria. ${ }^{47}$ Microdissection was performed as previously described. ${ }^{44}$ Briefly, after deparaffinization and staining of slides with hematoxylin and eosin, pancreatic tissue surrounding the PanIN lesion was first removed by blade and needle. The isolated PanIN lesion was then collected by scratching the slide after placing a drop of TK buffer $(200 \mu \mathrm{g} / \mathrm{ml}$ of proteinase $\mathrm{K}$ and $0.5 \%$ Tween 20 ) directly onto the microdissected tissue. The neoplastic cellularity of the microdissected PanINs has been estimated over 80\%. Generally, 2000-4000 cells were dissected per PanIN. Genomic DNA was extracted from the microdissected tissues by incubating in $50 \mu \mathrm{l}$ of TK buffer at $56^{\circ} \mathrm{C}$ overnight.

\section{Methylation-Specific Polymerase Chain Reaction}

DNA samples were treated with sodium bisulfite (Sigma Chemical Co., St Louis, MO, USA) for $16 \mathrm{~h}$ at $50^{\circ} \mathrm{C}$. After purification with the Wizard DNA cleanup system (Promega, Madison, WI, USA), $1 \mu \mathrm{l}$ of the bisulfite-treated DNA was amplified using primers specific for either methylated or unmethylated DNA. DNA was isolated and modified from an estimated average of 3000 cells or $10 \mathrm{ng}$ per PanIN, corresponding to an input DNA of $200 \mathrm{pg}$ per methylation-specific polymerase chain reaction (MSP) reaction. PCR conditions were as follows: $95^{\circ} \mathrm{C}$ for $5 \mathrm{~min}$; then 40 cycles of $95^{\circ} \mathrm{C}$ for $20 \mathrm{~s}$, $60-62^{\circ} \mathrm{C}$ for $20 \mathrm{~s}$, and $72^{\circ} \mathrm{C}$ for $30 \mathrm{sec}$; and a final extension of $4 \mathrm{~min}$ at $72^{\circ} \mathrm{C}$ (primer sequences are available upon request). A volume of $5 \mu \mathrm{l}$ of each PCR product was loaded onto $3 \%$ agarose gels and visualized by ethidium bromide staining.

\section{Statistical Analysis}

Statistical analysis was performed using $\chi^{2}$-test or Mann-Whitney $U$ non-parametric test. Differences were considered significant at $P<0.05$.

\section{Results}

\section{Identification of Genes Aberrantly Methylated in Invasive Pancreatic Cancer}

As previously reported, we used oligonucleotide microarrays to screen for genes that are induced after treatment of pancreatic cancer cells with the DNA methyltransferase inhibitor 5-aza-2'-deoxycytidine (5Aza-dC). Using this approach, we have identified a total of 475 genes that were markedly ( $>5$-fold) induced after 5Aza-dC treatment in pancreatic cancer cell lines but not in a non-neoplastic pancreatic epithelial cell line. ${ }^{26}$ Among this large panel of genes identified, eight genes were selected for the present analyses because these genes showed complete unmethylation in a panel of normal pancreatic ductal epithelia selectively microdissected using laser-capture microdissection. These eight genes were cadherin 3 ( $C D H 3)$, candidate mediator of the p53-dependent G2 arrest (reprimo), claudin 5 (CLDN5), LIM homeobox protein 1 (LHX1), neuronal pentraxin II (NPTX2), secreted apoptosis related protein 2 (SARP2), secreted protein acidic and rich in cysteine (SPARC), and suppression of tumorigenicity 14 (ST14).

\section{Methylation Analysis of Multiple Genes in PanINs}

DNA samples from a total of 65 PanIN lesions (17 PanIN-1A, 21 PanIN-1B, 15 PanIN-2, and 12 PanIN3 ) were analyzed in the present study. These PanIN lesions were derived from 20 pancreata resected for pancreatic ductal adenocarcinoma (11 patients, mean age of 62), chronic pancreatitis (4 patients, mean age of 58), and other neoplasms (5 patients, mean age of 67), including ampullary cancer, common bile duct cancer, well-differentiated 
pancreatic endocrine neoplasm, and mucinous cystic neoplasm. There was no significant difference in age between these three disease groups.

To detect methylation abnormalities in these microdissected PanIN samples, we utilized MSP. Using this sensitive assay, we were able to detect $p p E N K$ amplification from an initial $50 \mu \mathrm{l}$ of DNA samples containing $\sim 200-400$ cells dissected from archival tissues. ${ }^{44}$ Representative MSP results of $S A R P 2$ gene are shown in Figure 1. In most PanINs containing methylated alleles, unmethylated alleles were also detected in the same samples, reflecting contamination by normal cells (such as stromal cells and inflammatory cells), partial methylation of the CpG island, hemimethylation involving one allele of the gene, or clonal heterogeneity of neoplastic cells.

The overall prevalence of $\mathrm{CpG}$ island methylation at each gene locus was $30 \%$ for Reprimo, $28 \%$ for SPARC, $23 \%$ for SAPR2, $20 \%$ for NPTX2, $14 \%$ for $L H X 1,13 \%$ for $C L D N 5,13 \%$ for $C D H 3$, and $0 \%$ for ST14. We next compared the methylation patterns of each gene among different grades of PanIN (Figure 2). For several genes such as $C D H 3$

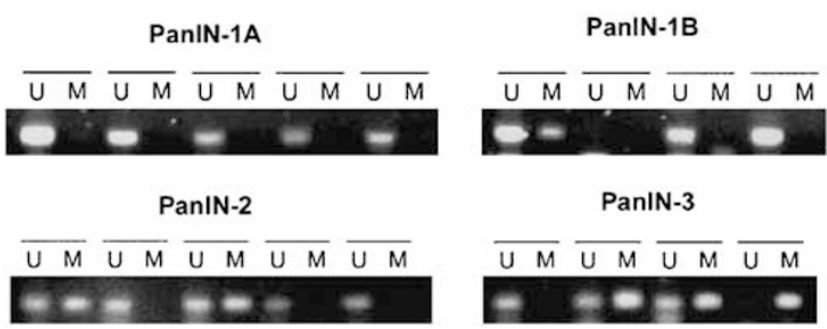

Figure 1 Methylation-specific PCR analysis of SARP2 in various grades of PanINs. The PCR products in lanes $\mathrm{U}$ and $\mathrm{M}$ indicate the presence of unmethylated and methylated templates, respectively.

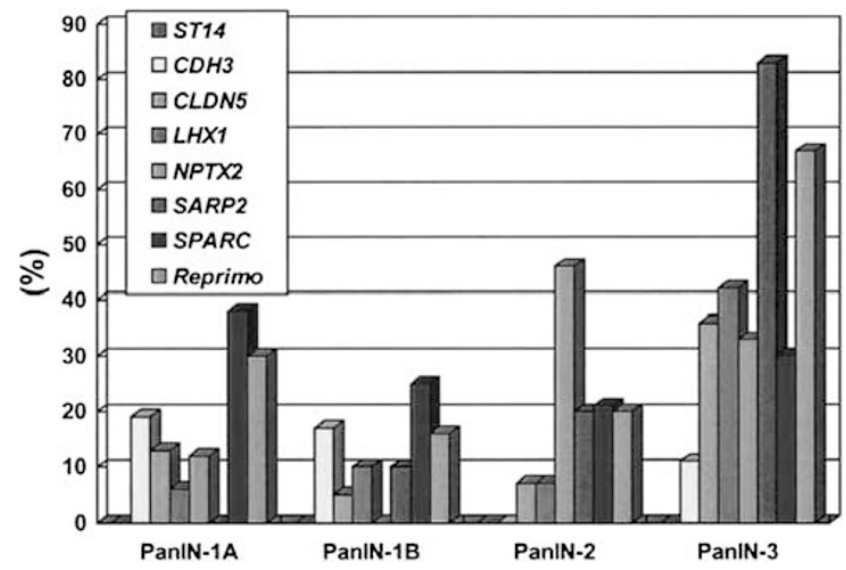

Figure 2 Frequency of aberrant $\mathrm{CpG}$ island methylation at eight genes in various grades of PanINs. The methylation frequency significantly increased from PanIN-1 to PanIN-2 for NPTX2 (6 vs $46 \%, P=0.0008$ ) and from PanIN-2 to PanIN-3 for $S A R P 2$ (20 vs $83 \%, P=0.001$ ), reprimo (20 vs $67 \%, P=0.01$ ), and $L H X 1$ (7 vs $42 \%, P=0.03$ ). and SPARC, the methylation frequencies were similar throughout all the PanIN grades. On the other hand, the prevalence of methylation at NPTX2 significantly increased from PanIN-1 to PanIN-2 (6 vs $46 \%, P=0.0008$ ). Furthermore, the methylation frequency significantly increased from PanIN-2 to PanIN-3 for SARP2 (20 vs $83 \%, P=0.001)$, reprimo (20 vs 67\%, $P=0.01$ ), and LHX1 (7 vs $42 \%, P=0.03)$. There was no correlation between methylation frequency for each gene and clinicopathological features including age, gender, and underlying disease (not shown).

The methylation profile of 10 genes (including ppENK and $p 16$ as previously reported ${ }^{44}$ ) for each PanIN lesion is summarized in Figure 3. Aberrant methylation of at least one of the eight genes examined was found in $44(68 \%)$ of the 65 PanIN lesions, including $12(71 \%)$ of the PanIN-1A, 12 $(57 \%)$ of the PanIN-1B, $9(60 \%)$ of the PanIN-2, and $11(92 \%)$ of the PanIN-3 lesions. The number of methylated loci for each PanIN lesion ranged from 0 to 6 , and the average number of methylated loci was 1.1 in PanIN-1A, 0.8 in PanIN-1B, 1.1 in PanIN-2, and 2.9 in PanIN-3, showing an increase from PanIN-2 to PanIN-3 and PanIN-1 to PanIN-3, but not from PanIN1 to PanIN-2 $(P=0.01$, MannWhitney $U$-test).

Of note, $6(9 \%)$ of 65 PanINs (1 PanIN-1A, 1 PanIN-2, and 4 PanIN-3) harbored aberrant methylation involving 4 or more of the 8 genes, suggesting a hypermethylator phenotype. These six lesions were derived from four resected pancreata from patients with an invasive cancer (three patients with pancreatic ductal adenocarcinoma and one patient with common bile duct carcinoma). Interestingly, 5 (83\%) of the 6 PanIN lesions with this phenotype showed concordant methylation at $p p E N K$, whereas only $4(7 \%)$ of the remaining 59 lesions showed methylation at this gene $(P<0.0001$; Figure 3$)$.

\section{Discussion}

In order to determine the timing and prevalence of CpG island hypermethylation during early pancreatic ductal carcinogenesis, we analyzed 65 PanIN lesions for methylation status of eight genes recently identified as aberrantly methylated in invasive pancreatic cancer but not in normal pancreatic ductal epithelium. We found aberrant methylation at multiple CpG islands in all grades of PanIN and a progressive increase in the overall methylation frequency from low-grade to high-grade PanINs. These results provide evidence that aberrant CpG island methylation is involved in early pancreatic ductal carcinogenesis and further support our previous findings of aberrant methylation of $p 16$, ppENK, and TSLC1 in a subset of PanINs.

In the present study, we were able to detect aberrant methylation even in the lowest grade PanIN lesions (PanIN-1A). Remarkably, aberrant 

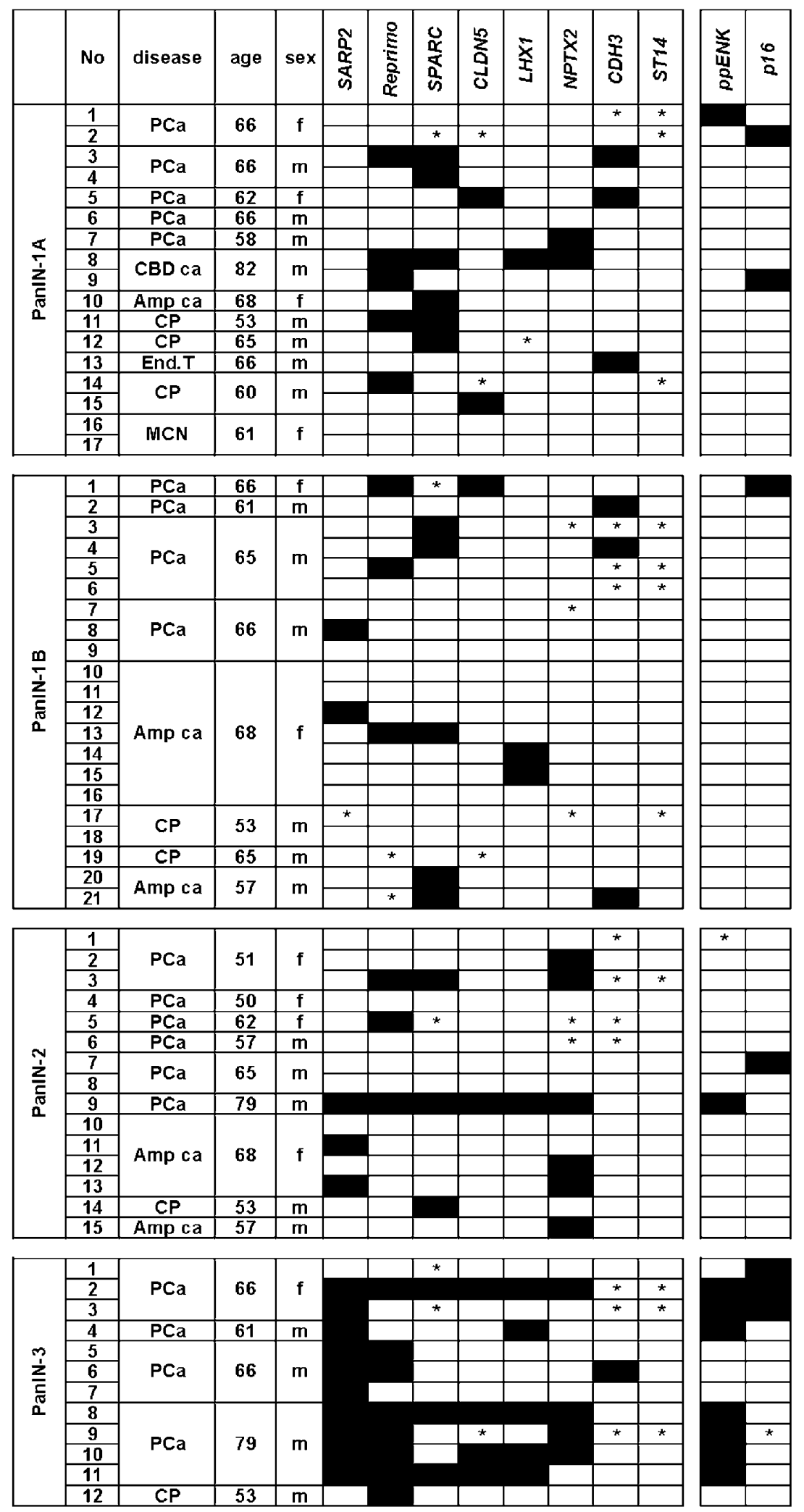

Figure 3 Methylation profiles of 10 genes (8 genes analyzed in this study and 2 genes ( $p p E N K$ and $p 16$ ) in a previous study) in PanINs determined by MSP. PCa, pancreatic adenocarcinoma; CP, chronic pancreatitis; CBD ca, common bile duct cancer; Amp ca, ampullary cancer; End.T, endocrine tumor; MCN, mucinous cystic tumor. Filled boxes, methylated alleles; open boxes, unmethylated alleles; *, not determined. 
methylation at any of the eight genes tested was identified in more than $70 \%$ of PanIN-1A lesions. Consistent with our present results, other investigators have reported aberrant methylation of several genes in the earliest neoplastic lesions (or even in non-neoplastic lesions associated with malignancy) of several other tumor types. For example, aberrant methylation of several CpG islands (including hMLH1 and HPP1) has been detected in aberrant crypt foci and hyperplastic polyps of the colon. ${ }^{48,49}$ Aberrant methylation of E-cadherin, hMLH1, and p16 has been frequently detected in non-neoplastic gastric epithelia in patients with gastric cancer. ${ }^{50}$ Similarly, hypermethylation of 14-3-3 sigma has been reported in atypical hyperplasias and apparently normal breast epithelium adjacent to breast cancer. ${ }^{51}$ These previous reports and our present results raise the possibility that aberrant $\mathrm{CpG}$ island methylation is one of the earliest events during neoplastic progression of human cancers.

We also observed that the average number of methylated loci significantly increased from PanIN2 to PanIN-3, suggesting that methylation abnormalities may play a major role in the transition from low-grade (PanIN-1 and PanIN-2) to high-grade PanINs (PanIN-3). A similar stepwise progression of methylation abnormalities has been implicated in the progression of various cancer types, including bladder cancer, ${ }^{52}$ gastric cancer, ${ }^{53}$ and esophageal cancer. ${ }^{54-58}$ Belinsky et $a l^{59}$ examined the timing for p16 methylation during sequential progression of squamous cell carcinoma of the lung and found that the methylation frequency increased during disease progression from basal cell hyperplasia $(17 \%)$ to squamous metaplasia (24\%) to carcinoma in situ $(50 \%)$ lesions. We previously demonstrated that aberrant methylation of multiple loci in another precursor lesion in the pancreas, intraductal papillary mucinous neoplasms of the pancreas (IPMN), increases with histological grade of malignancy. ${ }^{22}$ These findings suggest that progressive increase in methylation frequency may be involved in the sequential progression of various tumor types.

Many of the genes analyzed in this study have been found to be functionally important in a variety of cell functions such as cell cycle regulation (reprimo), cell proliferation and adhesion (SPARC), apoptosis (SARP2), cell adhesion ( $C D H 3)$, neuronal uptake or synapse formation (NPTX2), and tight junction barrier (CLDN5). For example, reprimo is a downstream mediator of p53-induced G2 cell cycle arrest, and its overexpression induces cell cycle arrest at the G2 phase, suggesting that it has tumorsuppressor properties. ${ }^{60}$ SPARC is a matricellular glycoprotein involved in diverse biological processes $^{61}$ and is frequently silenced by aberrant methylation in pancreatic adenocarcinomas. ${ }^{23} \mathrm{Sev}$ eral lines of evidence suggest a tumor-suppressor role of SPARC in certain tumor types. ${ }^{62-65}$ We have recently demonstrated that stromal SPARC patterns independently predict outcome in patients with pancreatic ductal adenocarcinoma. ${ }^{66}$ SARP2 is an apoptosis-related gene that interacts the Wnt oncogenic signaling pathway. ${ }^{67}$ Transfection of SARP2 into breast cancer cells results in an increased sensitivity to different proapoptotic stimuli, ${ }^{67}$ implying that epigenetic inactivation of $S A R P 2$ can confer cellular resistance to apoptosis. Therefore, aberrant methylation at these genes in PanIN lesions may contribute to neoplastic progression of pancreatic cancer, although the functional consequences of these epigenetic abnormalities remain to be determined.

By analyzing the methylation status of multiple genes, we found that the patterns of methylation during the progression of PanINs were variable among genes. For example, NPTX2 showed an increase in methylation prevalence from PanIN-1 to PanIN-2, whereas the prevalence of methylation at other genes such as SARP2 increased from PanIN-2 to PanIN-3. By contrast, some genes (eg, $S P A R C$ ) were aberrantly methylated at similar frequencies throughout all grades of PanINs. These results suggest that specific genes can be targeted for aberrant methylation at different stages of pancreatic neoplastic progression. The genes that are abnormally methylated in early low-grade PanIN lesions may be targets for chemoprevention, while those that are abnormally methylated in late high-grade lesions may be useful as markers of early detection.

In conclusion, by analyzing the $\mathrm{CpG}$ island hypermethylation profile at multiple genes in various grades of PanINs, we demonstrate a progressive increase in the prevalence of methylation with increasing histological grade of PanINs. Our present results provide further evidence for a role of epigenetic abnormalities in early pancreatic ductal carcinogenesis.

\section{Acknowledgement}

This work is supported by the SPORE in Gastrointestinal Malignancies (CA62924) and the Michael Rolfe Foundation.

\section{Conflict of interest/disclosure}

None.

\section{References}

1 Hruban RH, Adsay NV, Albores-Saavedra J, et al. Pancreatic intraepithelial neoplasia: a new nomenclature and classification system for pancreatic duct lesions. Am J Surg Pathol 2001;25:579-586.

2 Feldmann G, Beaty R, Hruban RH, et al. Molecular genetics of pancreatic intraepithelial neoplasia. J Hepatobiliary Pancreat Surg 2007;14:224-232. 
3 Hruban RH, Goggins M, Parsons J et al. Progression model for pancreatic cancer. Clin Cancer Res 2000; 6:2969-2972.

4 Moskaluk CA, Hruban RH, Kern SE. p16 and K-ras gene mutations in the intraductal precursors of human pancreatic adenocarcinoma. Cancer Res 1997;57: 2140-2143.

5 Wilentz RE, Geradts J, Maynard R, et al. Inactivation of the p16 (INK4A) tumor-suppressor gene in pancreatic duct lesions: loss of intranuclear expression. Cancer Res 1998;58:4740-4744.

6 Luttges J, Galehdari H, Brocker V, et al. Allelic loss is often the first hit in the biallelic inactivation of the p53 and DPC4 genes during pancreatic carcinogenesis. Am J Pathol 2001;158:1677-1683.

7 Wilentz RE, Iacobuzio-Donahue CA, Argani $\mathrm{P}$, et al. Loss of expression of Dpc4 in pancreatic intraepithelial neoplasia: evidence that DPC4 inactivation occurs late in neoplastic progression. Cancer Res 2000;60: 2002-2006.

8 Goggins M, Hruban RH, Kern SE. BRCA2 is inactivated late in the development of pancreatic intraepithelial neoplasia: evidence and implications. Am J Pathol 2000;156:1767-1771.

9 Hruban RH, Fukushima N. Pancreatic adenocarcinoma: update on the surgical pathology of carcinomas of ductal origin and PanINs. Mod Pathol 2007;20: S61-S70.

10 van Heek NT, Meeker AK, Kern SE, et al. Telomere shortening is nearly universal in pancreatic intraepithelial neoplasia. Am J Pathol 2002;161:1541-1547.

11 Brune K, Goggins M, O’Mailey L, et al. Detailed pathologic evaluation of non-invasive precursor lesions of the pancreas in patients with a strong family history of pancreatic cancer. Am J Surg Pathol 2006;30:1067-1076.

12 Canto M, Goggins M, Yeo CJ, et al. Screening for pancreatic neoplasia in high risk individuals. Clin Gastroenterol Hepatol 2004;2:606-621.

13 Canto MI, Goggins M, Yeo CJ, et al. Screening for pancreatic neoplasia in high risk individuals. Clin Gastroenterol Hepatol 2004;2:606-621.

14 Jones PA, Baylin SB. The fundamental role of epigenetic events in cancer. Nat Rev Genet 2002;3: 415-428.

15 Ueki T, Walter KM, Skinner $\mathrm{H}$, et al. Aberrant $\mathrm{CpG}$ island methylation in cancer cell lines arises in the primary cancers from which they were derived. Oncogene 2002;21:2114-2117.

16 Ueki T, Toyota M, Sohn T, et al. Hypermethylation of multiple genes in pancreatic adenocarcinoma. Cancer Res 2000;60:1835-1839.

17 Sato N, Rosty C, Jansen M, et al. STK11/LKB1 peutz-jeghers gene inactivation in intraductal papillary-mucinous neoplasms of the pancreas. Am J Pathol 2001;159:2017-2022.

18 Rosty C, Ueki T, Argani P, et al. Overexpression of S100A4 in pancreatic ductal adenocarcinomas is associated with poor differentiation and DNA hypomethylation. Am J Pathol 2002;160:45-50.

19 Ueki T, Toyota M, Skinner H, et al. Identification and characterization of differentially methylated CpG islands in pancreatic carcinoma. Cancer Res 2001;61: 8540-8546.

20 Jansen M, Fukushima N, Rosty C, et al. Aberrant methylation of the $5^{\prime} \mathrm{CpG}$ island of TSLC1 is common in pancreatic ductal adenocarcinoma and is first manifest in high-grade PanINs. Cancer Biol Ther 2002;1:293-296.

21 Fukushima N, Sato N, Ueki T, et al. Preproenkephalin and p16 gene CpG island hypermethylation in pancreatic intraepithelial neoplasia (PanIN) and pancreatic ductal adenocarcinoma. Am J Pathol 2002;160: 1573-1581.

22 Sato N, Ueki T, Fukushima N, et al. Aberrant methylation of $\mathrm{CpG}$ islands in intraductal papillary mucinous neoplasms of the pancreas increases with histological grade. Gastroenterology 2002;123: 1365-1372.

23 Sato N, Fukushima N, Maehara N, et al. SPARC/ osteonectin is a frequent target for aberrant methylation in pancreatic adenocarcinoma and a mediator of tumor-stromal interactions. Oncogene 2003;22: 5021-5030.

24 Sato N, Maitra A, Fukushima N, et al. Frequent hypomethylation of multiple genes overexpressed in pancreatic ductal adenocarcinoma. Cancer Res 2003; 63:4158-4166.

25 Fukushima N, Sato N, Sahin F, et al. Aberrant methylation of suppressor of cytokine signalling-1 (SOCS-1) gene in pancreatic ductal neoplasms. Br J Cancer 2003;89:338-343.

26 Sato N, Fukushima N, Maitra A, et al. Discovery of novel targets for aberrant methylation in pancreatic carcinoma using high-throughput microarrays. Cancer Res 2003;63:3735-3742.

27 Matsubayashi H, Sato N, Fukushima N, et al. Methylation of cyclin D2 is observed frequently in pancreatic cancer but is also an age-related phenomenon in gastrointestinal tissues. Clin Cancer Res 2003;9: 1446-1452.

28 Fukushima N, Walter KM, Ueki T, et al. Diagnosing pancreatic cancer using methylation specific PCR analysis of pancreatic juice. Cancer Biol Ther 2003;2:78-83.

29 Sato N, Fukushima N, Matsubayashi H, et al. Identification of maspin and S100P as novel hypomethylation targets in pancreatic cancer using global gene expression profiling. Oncogene 2003;29:29.

30 Sato N, Maehara N, Su GH, et al. Effects of 5-aza-2' deoxycytidine on matrix metalloproteinase expression and pancreatic cancer cell invasiveness. J Natl Cancer Inst 2003;95:327-330.

31 Sato N, Parker AR, Fukushima N, et al. Epigenetic inactivation of TFPI-2 as a common mechanism associated with growth and invasion of pancreatic ductal adenocarcinoma. Oncogene 2005;24:850-858.

32 Matsubayashi $\mathrm{H}$, Canto $\mathrm{M}$, Sato $\mathrm{N}$, et al. DNA methylation alterations in the pancreatic juice of patients with suspected pancreatic disease. Cancer Res 2006;66:1208-1217.

33 Sato N, Goggins M. The role of epigenetic alterations in pancreatic cancer. J Hepatobiliary Pancreat Surg 2006;13:286-295.

34 Sato N, Fukushima N, Chang R, et al. Differential and epigenetic gene expression profiling identifies frequent disruption of the RELN pathway in pancreatic cancers. Gastroenterology 2006;130:548-565.

35 Sato N, Goggins M. Epigenetic alterations in intraductal papillary mucinous neoplasms of the pancreas. J Hepatobiliary Pancreat Surg 2006;13:280-285.

36 Shi C, Eshleman SH, Jones D, et al. LigAmp for sensitive detection of single-nucleotide differences. Nat Methods 2004;1:141-147. 
37 Sato N, Fukushima N, Maitra A et al. Gene expression profiling identifies genes associated with invasive intraductal papillary mucinous neoplasms of the pancreas. Am J Pathol 2004;164:903-914.

38 Iacobuzio-Donahue CA, Ashfaq R, Maitra A, et al. Highly expressed genes in pancreatic ductal adenocarcinomas: a comprehensive characterization and comparison of the transcription profiles obtained from three major technologies. Cancer Res 2003;63:8614-8622.

39 Iacobuzio-Donahue C, Maitra A, Olsen M, et al. Exploration of global gene expression patterns in pancreatic adenocarcinoma using cDNA microarrays. Am J Pathol 2003;162:1151-1162.

40 Prasad NB, Biankin AV, Fukushima N, et al. Gene expression profiles in pancreatic intraepithelial neoplasia reflect the effects of Hedgehog signaling on pancreatic ductal epithelial cells. Cancer Res 2005;65:1619-1626.

41 Ryu B, Jones J, Hollingsworth MA, et al. Invasionspecific genes in malignancy serial analysis of gene expression comparisons of primary and passaged cancers. Cancer Res 2001;61:1833-1838.

42 Iacobuzio-Donahue CA, Anirban Maitra, Shen-Ong GL, et al. Discovery of novel tumor markers of pancreatic cancer using global gene expression technology. Am J Pathol 2002;160:1239-1249.

43 Sato N, Ueki T, Fukushima N, et al. Aberrant methylation of $\mathrm{CpG}$ islands in intraductal papillary mucinous neoplasms of the pancreas. Gastroenterology 2002;123:365-372.

44 Fukushima N, Sato N, Ueki T, et al. Aberrant methylation of preproenkephalin and p16 genes in pancreatic intraepithelial neoplasia and pancreatic ductal adenocarcinoma. Am J Pathol 2002;160:1573-1581.

45 Jansen M, Fukushima N, Rosty C, et al. Aberrant methylation of the $5^{\prime} \mathrm{CpG}$ island of TSLC1 is common in pancreatic ductal adenocarcinoma and is first manifest in high-grade PanlNs. Cancer Biol Ther 2002;1:293-296.

46 Peng DF, Kanai Y, Sawada M, et al. DNA methylation of multiple tumor-related genes in association with overexpression of DNA methyltransferase 1 (DNMT1) during multistage carcinogenesis of the pancreas. Carcinogenesis 2006;27:1160-1168.

47 Hruban RH, Adsay NV, Albores-Saavedra J et al. Pancreatic intraepithelial neoplasia: a new nomenclature and classification system for pancreatic duct lesions. Am J Surg Pathol 2001;25:579-586.

48 Chan AO, Issa JP, Morris JS, et al. Concordant CpG island methylation in hyperplastic polyposis. Am J Pathol 2002;160:529-536.

49 Chan AO, Broaddus RR, Houlihan PS, et al. CpG island methylation in aberrant crypt foci of the colorectum. Am J Pathol 2002;160:1823-1830.

50 Waki T, Tamura G, Tsuchiya T, et al. Promoter methylation status of E-cadherin, hMLH1, and p16 genes in nonneoplastic gastric epithelia. Am J Pathol 2002;161:399-403.

51 Umbricht CB, Evron E, Gabrielson E, et al. Hypermethylation of 14-3-3 sigma (stratifin) is an early event in breast cancer. Oncogene 2001;20:3348-3353.
52 Salem C, Liang G, Tsai YC, et al. Progressive increases in de novo methylation of $\mathrm{CpG}$ islands in bladder cancer. Cancer Res 2000;60:2473-2476.

53 Kang GH, Shim YH, Jung HY, et al. CpG island methylation in premalignant stages of gastric carcinoma. Cancer Res 2001;61:2847-2851.

54 Hamilton JP, Sato F, Jin Z, et al. Reprimo methylation is a potential biomarker of Barrett's-associated esophageal neoplastic progression. Clin Cancer Res 2006;12: 6637-6642.

55 Clement G, Braunschweig $\mathrm{R}$, Pasquier $\mathrm{N}$, et al. Alterations of the Wnt signaling pathway during the neoplastic progression of Barrett's esophagus. Oncogene 2006;25:3084-3092.

56 Wong DJ, Paulson TG, Prevo LJ, et al. p16(INK4a) lesions are common, early abnormalities that undergo clonal expansion in Barrett's metaplastic epithelium. Cancer Res 2001;61:8284-8289.

57 Bian YS, Osterheld MC, Fontolliet C, et al. p16 inactivation by methylation of the CDKN2A promoter occurs early during neoplastic progression in Barrett's esophagus. Gastroenterology 2002;122:1113-1121.

58 Eads CA, Lord RV, Kurumboor SK, et al. Fields of aberrant $\mathrm{CpG}$ island hypermethylation in Barrett's esophagus and associated adenocarcinoma. Cancer Res 2000;60:5021-5026.

59 Belinsky SA, Nikula KJ, Palmisano WA, et al. Aberrant methylation of p16(INK4a) is an early event in lung cancer and a potential biomarker for early diagnosis. Proc Natl Acad Sci USA 1998;95: 11891-11896.

60 Ohki R, Nemoto J, Murasawa H, et al. Reprimo, a new candidate mediator of the p53-mediated cell cycle arrest at the G2 phase. J Biol Chem 2000;275: 22627-22630.

61 Yan Q, Sage EH. SPARC, a matricellular glycoprotein with important biological functions. J Histochem Cytochem 1999;47:1495-1506.

62 Sansom OJ, Mansergh F, Evans M, et al. Deficiency of SPARC suppresses intestinal tumorigenesis in APCMin/+ mice. Gut 2007;56:1341-1343.

63 Said N, Motamed K. Absence of host-secreted protein acidic and rich in cysteine (SPARC) augments peritoneal ovarian carcinomatosis. Am J Pathol 2005;167: 1739-1752.

64 Puolakkainen PA, Brekken RA, Muneer S, et al. Enhanced growth of pancreatic tumors in SPARC-null mice is associated with decreased deposition of extracellular matrix and reduced tumor cell apoptosis. Mol Cancer Res 2004;2:215-224.

65 Brekken RA, Puolakkainen P, Graves DC, et al. Enhanced growth of tumors in SPARC null mice is associated with changes in the ECM. J Clin Invest 2003;111:487-495.

66 Infante JR, Matsubayashi H, Sato N, et al. Peritumoral fibroblast SPARC expression and patient outcome with resectable pancreatic adenocarcinoma. J Clin Onc 2007;25:319-325.

67 Melkonyan HS, Chang WC, Shapiro JP, et al. SARPs: a family of secreted apoptosis-related proteins. Proc Natl Acad Sci USA 1997;94:13636-13641. 